\title{
Transit Quality as an Integrated Traffic Management Strategy: Measuring Perceived Service
}

Matthew G. Karlaftis, John Golias, and Efstratios Papadimitriou

\section{Abstract}

Declining ridership, shrinking market share, and increasing operating costs have led many transit systems to adopt quality management strategies. These strategies help transit systems improve and evolve continuously by focusing on the customer (passengers) first. An integral step in adopting quality systems is measuring customer satisfaction. Using questionnaire data from the Athens, Greece, bus and trolley bus systems, this article demonstrates the potential use of structural equation modeling (SEM) for measuring customer satisfaction, and relays useful results regarding perceived service quality. The questionnaire results yield essential information in determining current and near-term requirements and customer expectations, helping set priorities for service improvements, identifying system weaknesses, targeting user groups and identifying their specific needs, and setting performance benchmarks that can be used to compare the system to its competitors and track its performance over time.

\section{Introduction}

As with most public and private firms that use traditional business practices, transit systems suffer from increasingly less efficient management (TCRP 1995). In many instances, management has not kept pace with changing societal demands and demographic patterns, shifting employee and customer 
expectations, increasing competition and fiscal constraints, and the need to adopt and use advanced technologies. This inability to satisfy changing market conditions has resulted in shrinking ridership figures, declining market share, increased operating costs, and reduced customer service.

In the past decade, amid talks for dramatic decreases in operating subsidies, transit management has been under pressure to control operating costs and recapture market share. In response, fares have frequently been increased, privatization (and service subcontracting) has been examined, and part-time workers have been hired (Obeng and Ugboro 199.9). While the results of these measures may vary, transit is still facing difficult times. Many transit systems are experimenting with quality management strategies, with frequently promising results (Obeng and Ugboro 1999). ' This quality-focused management helps an organization move from traditional outdated management to a more progressive way of running the company (transit system). Part of this process helps the organization learn how to improve and evolve continuously by focusing on people first: passengers, employees, and the community in general (TCRP 1995).

As in U.S. and international transit systems, the Athens Urban Transportation Organization decided to move toward a quality management environment. As part of this process, transit riders (customers) become the explicit service target, and the organization strives to offer a quality of service that meets, and, at a later stage exceeds, customer expectations. The organization believes that its success clearly depends on retaining current riders and attracting new ones. Further, a transit system that is well organized and offers high-quality service can be a very effective part of any traffic management strategy. Of course, a well-integrated traffic strategy needs to include issues such as parking strategies, high-occupancy vehicle (HOV) lanes, park-'n-ride policies, congestion pricing, etc. But, a qualitatively solid transit system should be the cornerstone of any such strategy. This article focuses on the narrower issue of transit quality viewed through the traffic management scope.

How should overall performance as well as more specific aspects of performance be surveyed and measured? This information, once collected and analyzed, can help determine current and near-term requirements and customer 
expectations, set priorities for service improvements, identify system weaknesses, target user groups and identify their specific needs, and set performance benchmarks that can be used to compare a system to its competitors and track its performance over time. Many different techniques have been used in the past to assess customer satisfaction, or perceived service quality. The most widely used techniques are simple bivariate correlation, regression analysis, factor analysis, and multidimensional scaling. An in-depth review of these techniques and their application to transit customer satisfaction can be found in TCRP (1998) and Weinstein (2000).

This article develops a performance and service-quality scheme based on SEM. The scheme allows for more complex and realistic performance assessment than do the previously mentioned methods. The article briefly describes the Athens urban transport system and discusses the data collection process. It also reviews the methodological approach used and presents the estimation results. In addition, the article assesses perceived quality for different user groups.

\section{Characteristics of the Greater Athens Urban Transport System}

The urban region of Athens, the capital of Greece, has an area of 1,470 $\mathrm{km}^{2}$ and a population of approximately 4.1 million people. During the last decade, the population of the greater Athens area has increased by about 10 percent; car ownership has also increased considerably, approaching 250 automobiles per 1,000 inhabitants. This has led to an increase in travel time by 26 percent in the last 12 years, which, along with the insufficient urban road network in the central areas, has led to a deterioration of traffic conditions in the capital. Further, the modal split has changed in favor of automobile travel, from an automobile-to-transit ratio of 40:45 to 54:32 (Table 1). For the Athens metropolitan area, there is a daily demand for 5,650,000 journeys (linked trips), with a $1,080,000$ two-hour peak demand. There are $6,300,000$ singlemode daily trips, a 26 percent increase in the last 12 years.

Athens is served by a mass transit system of 1,840 motor buses, 1,550 of which are in operation daily; 356 trolley buses, 290 of which are in operation daily; and 3 metro lines with 268 cars. The bus system is made up of 41 trunk lines, 116 central lines, 9 intermunicipal lines, 98 local-feeder lines, 8 express 


\begin{tabular}{|lcccc|}
\hline \multicolumn{5}{|c|}{ Table 1 } \\
Modal Split in the Athens Metropolitan Area \\
\hline Year & Public Transport & Automobile & Taxi & Walk \\
\hline 1983 & $40 \%$ & $45 \%$ & $6.0 \%$ & $9 \%$ \\
1996 & $31.7 \%$ & $54.5 \%$ & $6.0 \%$ & $7.8 \%$ \\
\hline
\end{tabular}

lines, and 6 school lines, with a total annual ridership of 403 million passengers. This ridership is complemented by 90 million annual riders from the trolley buses, and 92 million passengers from Metro's Line 1 (total bus and trolley system boardings appear in Figure 1). Transit providers serve a system that has faced a 3.5 percent annual increase in traffic during the last 10 years and that has 22 percent of its signalized intersection junctions in the center of this highly-congested city (levels of service E-F). Obviously, the provision for mixed-traffic transit services in such a congested network is very difficult.

\section{Data Collection}

The data commonly used to assess service quality and performance come from questionnaires. Excellent guides on how to develop transit-related questionnaires as well as examples of successful ones can be found in TCRP (1998,

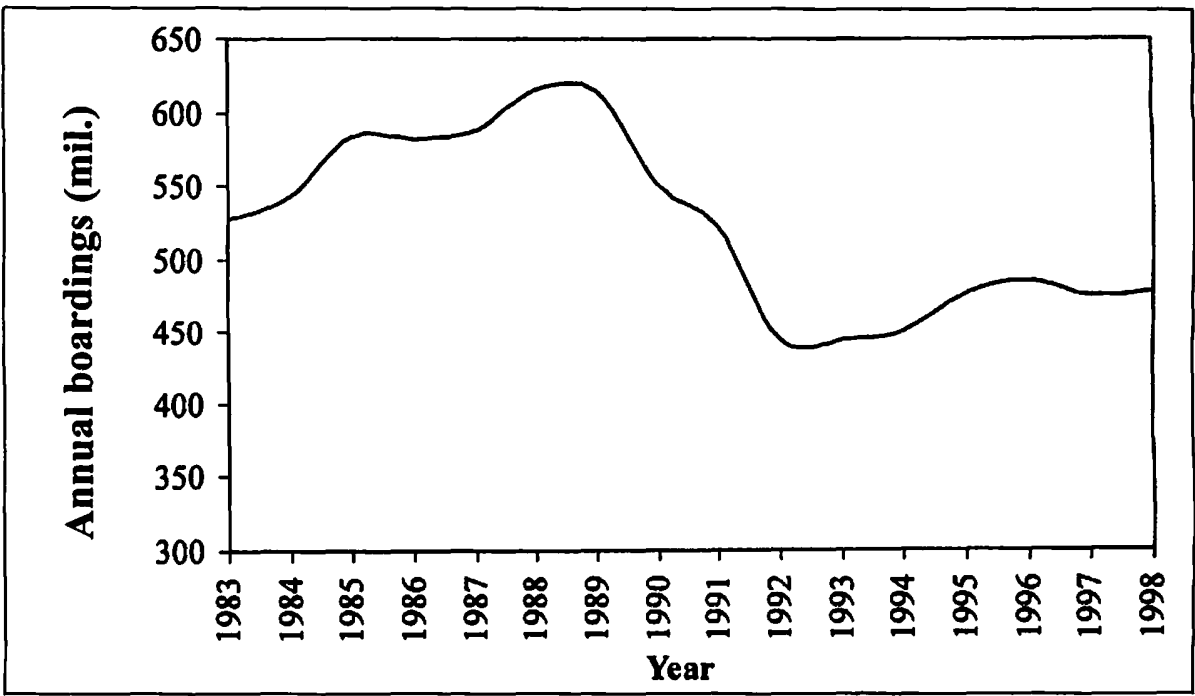

Figure 1. Annual ridership (boardings) for the Athens bus and trolley bus systems 
1999). The survey described in this article included 35 attributes (e.g., employee performance, security, customer service, comfort, bus environment, and trip performance), as well as socioeconomic characteristics for the respondents. The surveys were developed and completed using onboard, face-to-face interviews. ${ }^{2}$ To select the most representative sample of bus and trolley riders, a multistage stratified sampling process was followed.

The strata of the survey were the two main modes considered (buses and trolley buses) and the six different types of lines within the bus network (trunk, central, intermunicipal, local-feeder, express, special). From each stratum, a random sample of lines was selected, the size of which was proportional to the ridership of the stratum, with the probability of selecting each line proportional to its ridership (proportional to size sampling). Finally, weighted random sampling (using age and sex as the weights) was used to select the interviewed individuals. ${ }^{3}$

A total of 3,169 complete questionnaires were collected ( $83 \%$ from the buses and $17 \%$ from the trolleys). This number is quite high, especially when compared with other customer satisfaction surveys of systems with ridership figures similar to those of Athens. TCRP (1999) reports results of various studies using sample sizes between 300 and 500 respondents. ${ }^{4}$ The sample collected suggests that 71 percent of the riders use transit on a daily basis and 24 percent use the system one to three times a week. The sample of this study, and more generally the public using the system, is made up of frequent users as 95 percent of the individuals surveyed use transit at least weekly.

\section{The Methodological Approach}

This section examines the methodology used in this study and presents the estimation results.

\section{Structural Equation Modeling}

SEM, also known as latent-variable modeling, is a thorough technique for testing hypotheses for the relationship between observed and unobserved (latent) variables. The first account of the statistical theory underlying SEM appeared in the early 1970s (Joreskog 1973; Wiley 1973). The increasing complexity of the research questions examined and the appearance of user-friendlier SEM software packages increased the interest and use of the method as a standard approach to testing research hypotheses. 
The structural equation general models are defined by two components: the measurement model and the structural model. The measurement model is that component of the general model where latent variables are prescribed; it describes how well various exogenous variables measure latent variables. Latent variables are unobserved variables implied by the covariance structure among two or more observed indicators (variables). The structural model is that component of the general model where the relationship between latent variables and observed variables that are not indicators of latent variables are prescribed. Multiple regression, for example, is a structural model without latent variables, while classical factor analysis is a typical measurement model.

Following Joreskog and Sorbom (1993), the structural model can be written, in matrix form, as:

$$
\eta=\beta \eta+\Gamma \xi+\zeta
$$

where:

$\eta$ is an ( $m \times 1)$ vector of $m$ latent dependent variables.

$\xi$ is an $(n \times 1)$ vector of $n$ latent independent variables.

$\beta$ and $\Gamma$ denote the relationships among the latent variables. $\beta$ is an $(m$ $\mathrm{x} m$ ) matrix of structure coefficients that relate latent dependent variables to one another. $\Gamma$ is an $(m \times n)$ matrix of structure coefficients that relate the latent independent variables to the latent dependent variables.

$\zeta$ is the error term that contains the equation prediction errors or disturbance terms.

Similarly, the measurement model for the latent independent variables can be written as:

$$
\mathrm{X}=\Lambda_{\mathrm{x}} \xi+\delta
$$

where:

$\mathrm{X}$ is a $(q \times 1)$ vector of observed variables for the measures of the latent variables $\xi(n \times 1)$. 
( $q \times n)$ matrix $\Lambda_{\mathrm{x}}$ denotes the relationships between the observed variables and the latent variables (commonly termed factor loadings).

$(q \times 1)$ vector $\delta$ denotes the measurement errors for the Xs.

SEM, much like correlation, multiple regression, and analysis of variance (ANOVA), is a linear statistical method. Interestingly, standard linear models, such as linear regression and ANOVA, can be treated as special cases of the general structural equation model. SEM suffers from some of the same problems as the other linear techniques: models are valid only if certain underlying assumptions are met, and none of the methods offer statistical tests of causality. But, unlike the other methods, SEM has the capacity to estimate and test relations between latent variables. The ability to deal successfully with latent variables makes SEM useful and popular with performance and customer satisfaction studies. SEM has some similarities to Multidimensional Scaling (MDS), another very popular transit market research technique. However, while the primary goal of SEM analysis is to uncover the underlying relationships between observed variables and reduce them to a smaller number of latent factors, MDS is used to produce quadrant maps and perform SWOT (Strengths-Weaknesses-Opportunities-Threats) analyses.

\section{Estimation Results}

The initial step in the estimation process was to perform an exploratory factor analysis procedure, uncover some of the most basic relationships between the variables, and determine the approximate number of factors (latent variables) to retain as a first step (initial measurement model estimation). ${ }^{5}$ Once the relationships became clearer, the structural model was also estimated. The Wald and Lagrange multiplier tests were used for the modifications and testing. These two tests are used to evaluate the $X^{2}$ change as a result of respecifying one or more of the parameters. The maximum likelihood estimation was used to overcome the violations of the normality assumption necessitated by the method. The final model, after a series of modifications and testing, appears in Figure 2.

The path diagram shown in Figure 2 is a pictorial representation of the estimated structural equation model. Rectangles are used to indicate observed variables; ellipses, latent variables; straight arrows, association in one direction (from predictor to outcome); and curved arrows, nondirectional association 


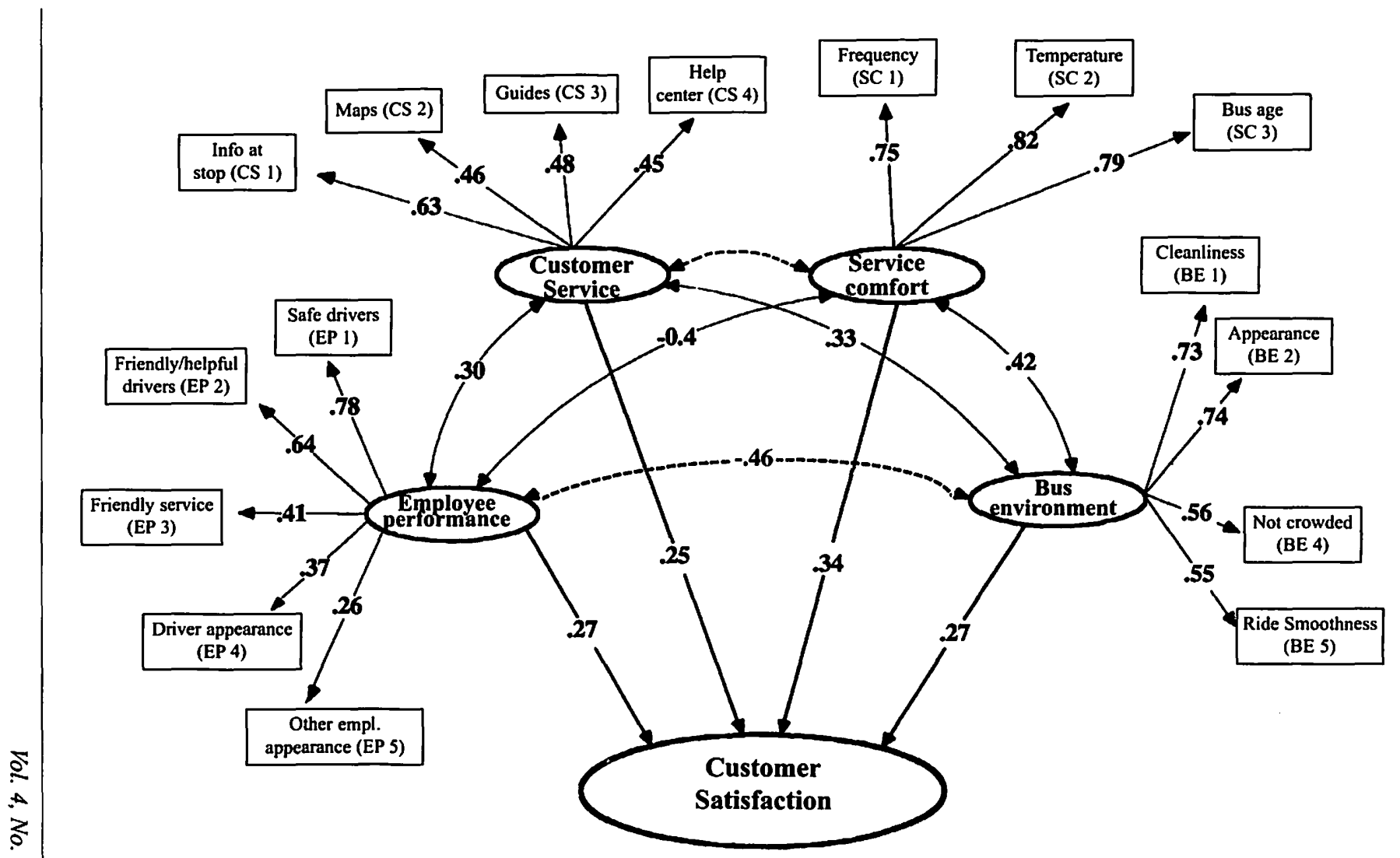

Figure 2. Final model specification 
(correlation). Numbers appearing on the arrows show the standardized parameter estimates that indicate the strength of association or correlation. Standardized parameter estimates are transformations of unstandardized estimates that remove scaling information and, therefore, allow for parameter comparisons in a model. Standardized parameter estimates index the number of standard deviations change in the dependent variable when all remaining independent variables are at zero.

The final model shows that there are four latent independent variables (first level of customer satisfaction assessment): employee performance, customer service, service comfort, and bus environment (the "names" for the latent independent variables were selected based on the observed variables that affect them). Interestingly, many of these latent variables and the indicators that affect them are similar to work performed by other transit systems (TCRP 1998, 1999; Weinstein 2000; Stuart et al. 2000). These latent variables (factors) correspond to four essential dimensions of a transit system's performance and four aspects of perceived service quality. The factors are:

- Employee performance measures the perceived service quality (from a customer's perspective) as it pertains to employees. Safe driving and driver helpfulness are the most important determinants of this factor, with general friendly service, driver appearance, and other employee appearance scoring much lower.

- Customer service is mainly characterized by the quality of information riders receive at the stops. Quality of available maps, help received from travel guides, and the phone center score lower.

- Service comfort is almost equally affected by service frequency, bus temperature (including air-conditioning availability), and age of the bus.

- Bus environment is affected by bus cleanliness, general appearance, and ride smoothness, with ease of paying fare, not crowded buses, and quality of stops and shelters scoring lower.

All the factors are correlated. In particular, employee performance and bus environment, service comfort and bus environment, and employee perfor- 
mance and customer service show statistically significant correlations of .46 , .42 , and .30 respectively. (While these correlation coefficients may seem low for usual bivariate correlation, they are quite high for SEM purposes.) Interestingly, the variables "Ease paying fare (BE3)" and "Ride smoothness (BE5)," both loading on the latent variable "Bus environment," could be included in the "Service comfort" latent variable. Initially, while an explicit effort was made to load variables BE3 and BE5 on the "Service comfort" latent variable, the two variables not only had very low coefficients, but also made the fit of the other three variables worse. As such, the decision was made to maintain the latent structure as it currently appears in Figure 2. Even if variables BE3 and BE5 were completely excluded from the model, the results would not be significantly affected because of their rather low correlation. Further, the positive correlation between "Service comfort" and "Bus environment" allows for these variables to be, indirectly at least, related to both latent variables.

A second latent-variable level (dependent latent variable) was then introduced. The four factors were introduced in a new model (structural model) as latent independent variables, with (overall) customer satisfaction forming the dependent latent variable. This dependent variable is intended to capture the overall system customer satisfaction levels. As a measure, this is very important since it yields a single customer satisfaction index that can be traced over time and compared to those of other systems. The results show that service comfort is clearly the most important determinant of customer satisfaction, with employee performance, customer service, and bus environment being approximately of equal importance. Finally, the model, using a variety of goodness-of-fit measures, shows a good fit to the data. (Root Mean Square Error, Akaike's Information Criterion, Browne-Cudeck Criterion, and TuckerLewis Index were used for goodness-of-fit purposes.) That is, the structural equation model presented in Figure 2 is a well-fitting model of a transit system's customer satisfaction levels.

\section{Assessing Perceived Quality}

In general, the goal of SEM analysis is to estimate a relatively simple structure in which each variable loads highly (high correlations are considered those over .5) on only one latent variable with small, and statistically not sig- 
nificant, loadings on all other latent variables. (In this article, since the observed variables loaded high on only one latent variable at a time, they were not "loaded" on the other latent variables.) As was discussed, the variables that load highly on one latent variable will help to interpret the "meaning" of that variable. The estimated parameters from the latent variables are then used to assign scores to each observation.

These scores are frequently called "factor scores" and, unlike the standardized parameter estimates that are used to assess the impact of various observed variables on the independent latent variables, they use the standardized parameter estimates as an input to obtain a single index. That is, factor scores can be used to obtain a score on all, independent and dependent, latent variables using the raw scores that customers gave for each of the observed variables. From the original answers and using the factor scores, analysts can infer, in index form, the various aspects of customer satisfaction.

A number of different methods have been proposed to estimate factor scores. One simple procedure adds, with equal weights, the values on the observed variables that are most highly correlated with the factor-a robust and rather extensively used approach. However, the most widely used method recognizes that the desire is to predict the latent variable, the factor, from a set of observed variables. Multiple regression is an accepted way of making predictions of a given variable from a set of explanatory variables. For this analysis, the regression method (Bollen 1989) to estimate factor scores is used. Table 2 presents the factor score weights for customer satisfaction yielded by the model presented in Figure 2.

The existence of such scores allows for a more formal and in-depth examination of the characteristics of customer satisfaction. ${ }^{6}$ Figure 3 presents the mean factor scores for various age groups. The scores for all latent variables do not show much variation for the different age groups. As such, it can be inferred that age is not a significant determinant of overall customer satisfaction. Figure 4 presents mean scores for the three income levels. Interestingly, higher-income riders tend to be less satisfied with the transit system. This could potentially happen because these customers compare the transit system to their private auto. Figure 5 shows mean scores for frequent and infrequent users. Frequent users, a focus group for this investigation, tend to give higher scores to the transit system. 
Table 2

Factor Score Weights for Customer Satisfaction Measurement

Latent

$\begin{array}{ll}\text { Variable } & \text { Observed Variable" }\end{array}$

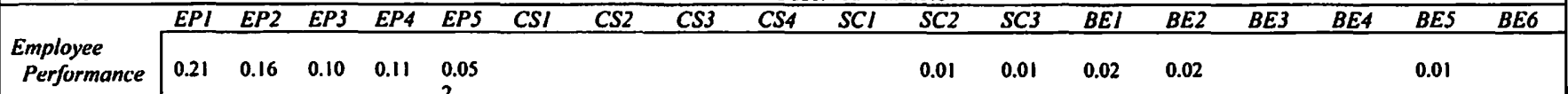

Employee

0.01

Bus

Environment

0.03

0.01

$-0.01$

$-0.04$

$-0.03 \quad 0.22$

Customer

Service

$\begin{array}{ll}0.06 & 0.01\end{array}$

0.03

0.25

0.11

0.12

0.09

$\begin{array}{cccc}-0.01 & -0.01 & 0.04 & 0.04\end{array}$

0.27

$0.08 \quad 0.07$

Service
Comfort

Overall

Customer

Satisfaction

"See Figure 2 for explanation of variables. Empty cells signify factor scores $<0.005$. 


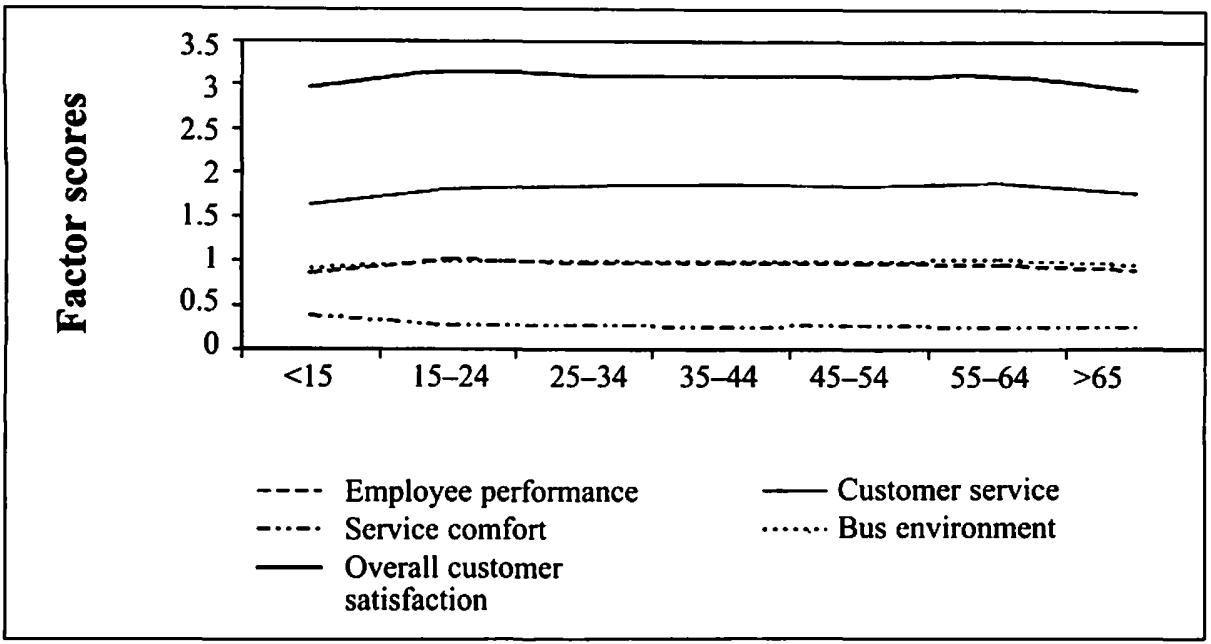

Figure 3. Factor scores for various age groups

Results of high importance to the transit systems appear in Figure 6, where mean scores are presented for the variety of line types operated by the transit system. ${ }^{7}$ A within-system trend is clearly visible. Trunk lines receive, by far, the lowest scores, and express lines receive the highest. Interestingly, trunk lines have the highest service frequency. Nevertheless, buses serving these lines are frequently packed, with all the problems that follow packed buses, and customers award them low scores. Similarly, it also seems that central lines

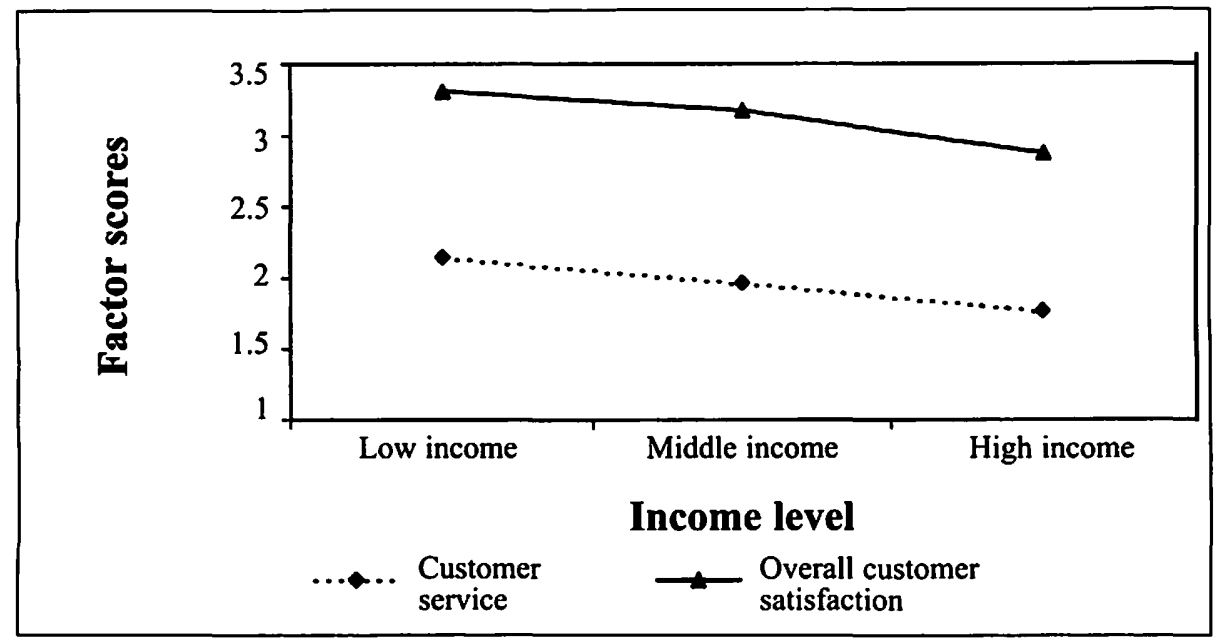

Figure 4. Customer satisfaction scores for various income levels 


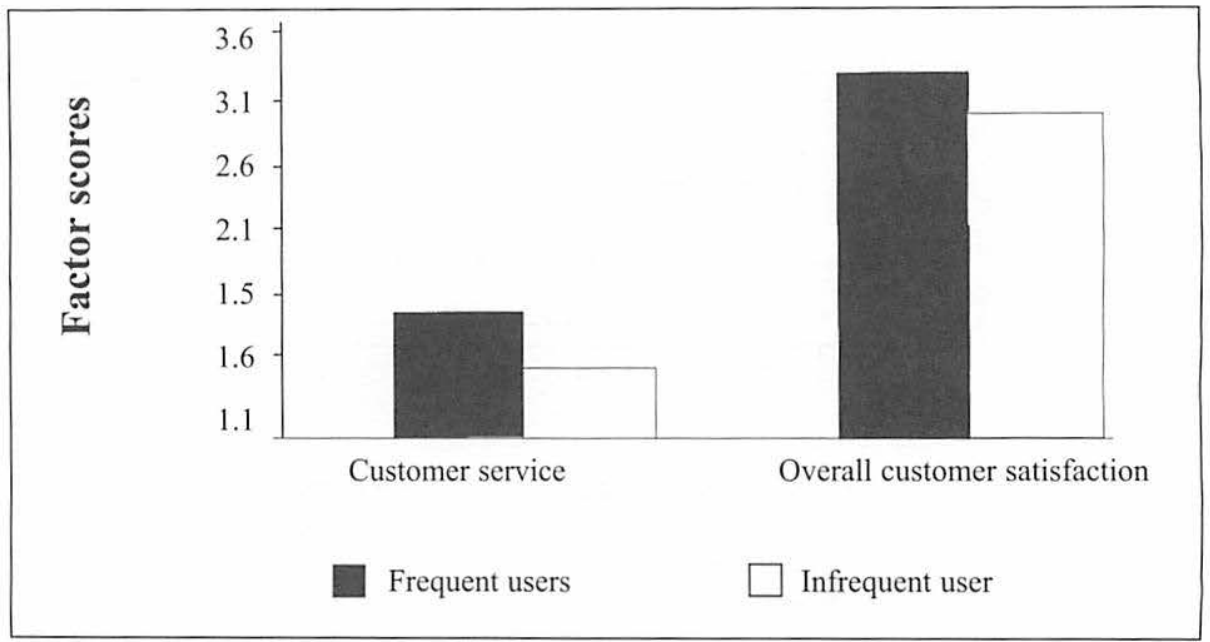

Figure 5. Customer satisfaction scores for frequence of use

suffer from the same problems as trunk lines. Express lines, which receive the highest scores, are served by the newest, air-conditioned buses have lower travel times, and are less packed than other lines. From these results it becomes clear that, to increase customer satisfaction, the Athens Urban Transport Organization needs to increase the quality of service in trunk, central, and intermunicipal lines.

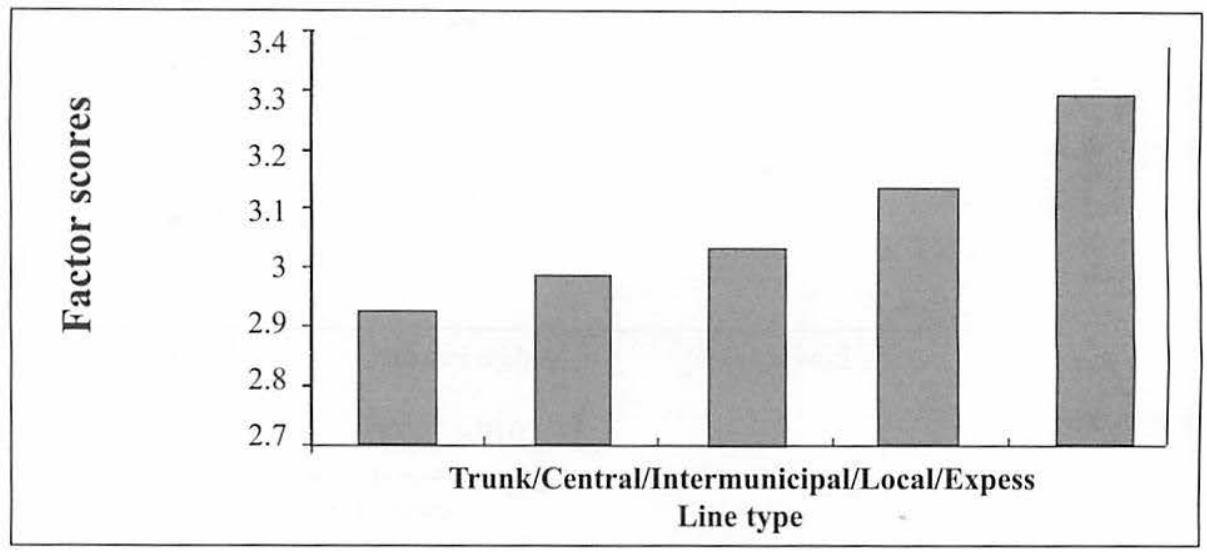

Figure 6. Customer satisfaction scores for various line types 


\section{Conclusions}

Faced with declining ridership numbers, shrinking market share, decreasing operating subsidies, and increasing operating costs, many transit systems are experimenting with quality management strategies. Quality-focused management helps an organization move from traditional, outdated management to a more progressive, effective, and efficient way of running the transit system. Part of this process helps the organization learn how to improve and evolve continuously by putting the customer (passengers) first. Another part of this strategy considers transit as an indispensable part of every integrated transport management strategy. As such, it is necessary for a transit system to offer an attractive, high-service-quality alternative to other modes of transport.

An important component of any quality-focused management is measurement of customer satisfaction. This information is essential in determining current and near-term requirements and customer expectations, helping set priorities for service improvements, identifying system weaknesses, targeting user groups and identifying their specific needs, and setting performance benchmarks that can be used to compare a system to its competitors and track its performance over time. The purpose of this article was to present a customer satisfaction scheme based on SEM. This scheme allows for more realistic and useful performance assessment than do the previously utilized methods. This assessment explicitly evaluates both overall customer satisfaction and its various separate dimensions.

Using survey data from an onboard, face-to-face interview questionnaire from Athens, Greece, this article demonstrates both the potential use of the proposed methodology and the factor scores obtained for various user subgroups. These scores indicate that the transit system examined needs to upgrade service provided in certain lines (trunk, central, intermunicipal), while it attempts to offer service levels that will satisfy higher-income users, hopefully diverting them from their automobiles. Finally, this same survey should be repeated annually, to allow the transit system to track its performance over time.

\section{Endnotes}

1. Interestingly, in the quality world, Total Quality Management is being replaced by Six Sigma. The Six Sigma strategy, originally instituted by 
Motorola during the 1980s, is a statistical term that means "six standard deviations from a statistical performing average." While many of the tools are the same, Six Sigma has a very clearly defined toolbox and would be very useful for transit agencies (Armstrong and Kotler 2000).

2. Surveys were collected for buses, trolley buses, and Metro's Line 1. The results from the surveys of the first two modes are presented here. For space considerations the exact survey instrument is not presented; it is available from the authors upon request.

3. A computer program was also used to test different combinations of sample sizes per stratum to identify the most effective sampling process, at the 95 percent level of significance.

4. Similar to many other customer satisfaction surveys, a four-point scale was used for the answers to the questions of this survey. That is, the responders could pick answers that ranged from "very satisfied" to "very unsatisfied."

5. SAS's PROC FACTOR was used for this initial analysis. PROC FACTOR's power and flexibility in exploratory factor analysis made it a very useful tool for this step of the analysis.

6. Once factor score weights (Table 2) have been estimated, it is very simple to estimate factor scores. The factor scores used in this article, for example, have been estimated using a spreadsheet program.

7. While the results presented here cover one year of data, many interesting insights can be gained by examining the evolution of a system's quality over time. This is the goal of the American Customer Satisfaction Index, which tracks customer satisfaction in more than two dozen U.S. manufacturing and service industries. Based on some of the findings of this index, overall customer satisfaction has been declining slightly in recent years, and it is unclear whether this has resulted from a decrease in product and service quality or from an increase in customer expectation. It will be interesting, at a later stage, to examine the evolution of a transit system's (and the industry's) quality, over time. 


\section{References}

Armstrong, G., and P. Kotler. 2000. Marketing: An introduction. New Jersey: Prentice-Hall.

Bollen, K. A. 1989. Structural equations with latent variables. New York: Wiley and Sons.

Joreskog, K. G. 1973. A general method for estimating a linear structural equation system. In A. S. Goldberger and O. D. Duncan (eds.), Structural equation models in the social sciences, 85-112. New York: Academic.

Joreskog, K. G., and D. Sorbom. 1993. LISREL 8: Structural equation modeling with the SIMPLIS command language. Hillsdale, NJ: Erlbaum.

Obeng, K., and J. Ugboro. 1999. Application of TQM in public transit firms. Transportation Quarterly 50(3): 79-84.

Stuart, K. R., M. Mednick, and J. Bobkman. 2000. A structural equation model of customer satisfaction for the New York City subway system. Paper presented at the Transportation Research Board Annual Meeting, Washington, DC.

TCRP. 1995. The quality journey: A TQM roadmap for public transportation. Washington, DC: Transportation Research Board.

TCRP. 1998. A handbook: Integrating market research into transit management. Washington, DC: Transportation Research Board.

TCRP. 1999. A handbook for measuring customer satisfaction and service quality. Washington, DC: Transportation Research Board.

Weinstein, A. 2000. Customer satisfaction among transit riders: How do customers rank the relative importance of various service attributes? Paper presented at the Transportation Research Board Annual Meeting, Washington, DC.

Wiley, D. E. 1973. The identification problem for structural equation models with unmeasured variables. In A. S. Goldberger and O. D. Duncan (eds.), Structural equation models in the social sciences, 69-83, New York: Academic. 


\section{About the Authors}

MaTtHew G. KaRLAFTis (mgk@central.ntua.gr) received his Ph.D. in civil engineering from the School of Civil Engineering at Purdue University in Indiana. His research interests include transportation statistics, traffic engineering, management and safety, public transportation, and the deployment of Intelligent Transportation Systems (ITS) technologies. His current position is lecturer in the Department of Transportation Planning and Engineering of the National Technical University of Athens.

JoHN GoLIAS (igolias@central.ntua.gr)is a civil engineer with more than 20 years of expertise in Greek and international projects and research in the field of highway and traffic engineering, road safety, and transportation planning. He is the author of a number of published papers in these areas. He is an associate professor in the Department of Transportation Planning and Engineering of the National Technical University of Athens.

EFstratios Papadimitriou (stratos@ath.forthnet.gr) received his Ph.D. in civil engineering from the Polytechnic Institute of New York. His research interests include transportation management, freight logistics, and public transportation. He is an assistant professor in the Department of Maritime Studies at the University of Piraeus, and managing director of the Athens Urban Transportation Organization. 